ARTíCulOS

ARTICLES 



\title{
EL DERECHO CONSTITUCIONAL DEL ABORTO EN LOS ESTADOS UNIDOS: UNA INTRODUCCIÓN *
}

\author{
Ian Shapiro ** \\ Universidad de Yale
}

RESUMEN. El autor expone y examina la jurisprudencia en torno al derecho constitucional al aborto en los Estados Unidos: desde el célebre caso Roe vs. Wade de 1973 hasta el caso Planned Parenthood of Southeastern Pennsy/vania vs. Casey en 1992. En el primero, se estableció que las mujeres tenían el mencionado derecho en los estadios tempranos del embarazo, de acuerdo con cierta segmentación trimestral de éste; mientras que, en el segundo caso, aunque se reafirmó el derecho constitucional al aborto, por un lado, se tomó distancia del esquema de análisis basado en trimestres y acuñó en cambio la noción de cargas indebidas, y por otro lado, se sostuvo inequívocamente que el interés del Estado en la vida potencial empieza después del momento en el cual el feto es viable. Shapiro reconstruye el proceso de mutación constitucional acaecido entre Roe y Case; para ello, no sólo aborda el paulatino giro producido en las rationes decidendi de los fallos de la Corte Suprema de los Estados Unidos, sino también las modificaciones ocurridas en la integración de ésta, así como las variaciones suscitadas en el contexto del debate público norteamericano en aquel lapso.

Palabras clave: aborto, Roe vs. Wade, Planned Parenthood of Southeastern Pennsylvania vs. Casey.

ABSTRACT. The author presents and examines the case law concerning the constitutional right to abortion in USA: from the well-known 1973 Roe vs. Wade case to the 1992 Planned Parenthood of Southeastern Pennsylvania vs. Casey case. In the first case, it was established that women had the above mentioned right in the early stages of pregnancy, in accordance with a division of pregnancy into three month terms; while, in the second case, despite the confirmation of the constitutional right to abortion, there was a distancing from the analysis scheme based on terms and, instead, the notion of undue burdens was coined. It was also clearly held that state interest in potential life begins the moment that the foetus is viable. Shapiro reconstructs the constitutional mutation process which took place between Roe and Casey; in order to do so, he approaches not only the gradual change of direction produced in the rationes decidendi of the U.S. Supreme Court rulings, but also the modifications which ocurred in the integration of the above mentioned mutation, as well as the variations arising in the context of the North American public debate in that space of time.

Keywords: abortion, Roe vs. Wade, Planned Parenthood of Southeastern Pennsylvania vs. Casey.

* Fecha de recepción: 31 de agosto de 2008. Fecha de aceptación: 18 de septiembre de 2008.

** Título del original: «The Constitutional Law of Abortion in the United States: an Introduction». Se trata del trabajo introductorio al libro Abortion. The Supreme Court Decisions 1965-2007, Hacket Publishing Company, Inc., Indianápolis/Cambridge, 2007. 


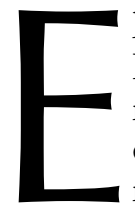

1 debate estadounidense sobre el aborto es a la vez apasionado e implacable. Enraizado en creencias poderosamente sostenidas, parece oponer visiones del mundo irreconciliables entre sí. Las convicciones religiosas acerca de que el feto es una persona, y por lo tanto el aborto un homicidio, colisionan precipitadamente con la afirmación insistente e incondicionada de que la vida comienza con el nacimiento. Aquellos que creen que la pobreza global, el cambio climático y la explosión demográfica son los problemas más difíciles que enfrenta la humanidad se hallan a sí mismos incrédulos frente a líderes espirituales que recorren el mundo condenando el aborto e incluso la contracepción. Las políticas gubernamentales tendentes a limitar la tasa de natalidad a través del aborto y la planificación familiar son vistas por algunos como lúcidas y necesarias; para otros, equivalen a una deliberada e injustificada interferencia con derechos humanos inviolables. Las creencias poderosamente sostenidas de que las mujeres tienen derecho al control soberano de sus cuerpos colisionan con creencias igualmente firmes respecto a que el embarazo acarrea la responsabilidad —aun si no es bienvenida - de llevar el embarazo a término. Hasta el homicidio ha parecido como justificado a los ojos de algunos a los fines de prevenir la realización de un aborto. «Ninguna decisión judicial en nuestros días», escribe R. DWORKIN en referencia a la decisión que la Corte Suprema adoptó en 1973 en Roe vs. Wade, que estableció que las mujeres poseían un derecho constitucionalmente protegido al aborto en los estadios tempranos de embarazo, «ha suscitado tanta indignación, pasión y violencia física por parte del público, o tanta intemperante crítica profesional» ${ }^{1}$.

A. MACINTYRE va más allá, al sostener que la característica más llamativa del debate moderno acerca del aborto es su carácter interminable. Las visiones que son enfrentadas una contra la otra, son «conceptualmente inconmensurables» en tanto que aunque son internamente consistentes, cada una se apoya sobre premisas rivales, las que «son de tal clase que no poseemos ningún modo racional de evaluar las pretensiones de una en comparación con las de la otra» ${ }^{2}$. Las ambivalencias profundas y las emociones conflictivas que las personas sienten en relación con el aborto fueron bien reflejadas en una encuesta de opinión a nivel nacional que The Angeles Times realizó en 1989. La encuesta reveló que aunque el 61 por 100 de los estadounidenses piensa que el aborto es moralmente incorrecto y el 57 por 100 piensa que es un homicidio, el 74 por 100 cree no obstante que «el aborto es una decisión que tiene que ser tomada por cada mujer por sí misma»33.

A pesar de todos sus impulsos contradictorios —en verdad, quizás parcialmente a causa de ellos- parece que las personas también esperan resolver el debate acerca del aborto. Se discute sobre él en los libros, en las diversas legislaturas y en los medios de comunicación. Unos están en desacuerdo con el razonamiento de los otros e invocan estadísticas que reconocen como decisivas para algún aspecto u otro del asunto. Del mismo modo que perciben, quizás, que es imposible alcanzar solución a la controversia acerca del aborto, en algún nivel muchas personas no pueden aceptar esa imposibilidad. Debe haber una solución razonable para el debate, parecen pensar; el problema es cómo alcanzarla.

\footnotetext{
${ }^{1}$ Dworkin, 29 de junio de 1989: «The Great Abortion Case», New York Review of Books, p. 49.

2 MacInTyre, 1984: After Virtue: A Study in Moral Theory, 2. ${ }^{a}$ ed., Notre Dame, Ind.: University of Notre Dame Press, pp. 6-8.

${ }^{3}$ Citado en Dworkin, «The Great Abortion Case», p. 49.
} 
La Corte Suprema de los Estados Unidos por más de tres décadas ha estado involucrada en una contienda sobre el problema del aborto. La decisión de 1973 en Roe vs. Wade, apoyada por una mayoría de siete a dos en la Corte Suprema parecía ser en aquel momento una resolución concluyente de la controversia. Sin embargo, aquellos que esperaban que esta decisión resolviera el asunto al remover el problema del aborto del ámbito del tenso debate político, fueron rápidamente defraudados. Si algo produjo Roe, fue que pareció intensificar y polarizar aun más el debate público acerca del aborto. No ha habido estabilidad en la posición de la Corte Suprema acerca del problema del aborto en los años que siguieron desde que Roe fue dictado. Aunque el derecho reconocido en aquella decisión fue reafirmado por una clara mayoría de la Corte Suprema en Planned Parenthood of Southeastern Pennsylvania vs. Casey ${ }^{4}$ en junio de 1992, tanto el contenido del derecho en cuestión como la base jurisprudencial sobre la que descansa evolucionaron sustancialmente en un número de decisiones de la Corte Suprema dictadas durante las dos décadas que mediaron entre un fallo y otro. En efecto, como resultará claro más adelante en este trabajo, el razonamiento sobre el que se fundaba la decisión original Roe ha sido en gran medida abandonado por la Corte Suprema.

Parte de la evolución en el entendimiento de la Corte Suprema del derecho a abortar refleja cambios en su composición. En 1973, los jueces William Rehnquist y Byron White fueron los únicos disidentes del voto mayoritario cuyo autor fue el juez Harry A. Blackmun. En dos décadas, Rehnquist fue Presidente de la Corte Suprema, y gran parte de la mayoría que adoptó la decisión original de Roe se había ido. William Douglas, Potter Stewart, Warren Burger, Lewis Powell, William Brennan, Thurgood Marshall y Blackmun, todos ellos se habían jubilado (al igual que el otro juez disidente de Roe, el juez White) y habían sido reemplazados por los jueces John Paul Stevens, Sandra Day O'Connor, Antonin Scalia, Anthony Kennedy, David Souter, Clarence Thomas, Ruth Bader Ginsburg y Stephen Breyer. Todos los reemplazantes, a excepción de Ginsburg y Breyer (seleccionados por el Presidente Bill Clinton en 1993 y 1994), fueron personas seleccionadas por los republicanos, las cuales estaban en diversos grados incómodas con el razonamiento de Roe, con su resultado o con ambas cosas. En efecto, era sabido que aun GINSBURG estaba incómoda con aspectos del razonamiento. Este grupo de jueces continuó desempeñando sus funciones en forma conjunta por más de una década hasta el verano del 2005, cuando la jueza O'Connor anunció su jubilación y el Presidente de la Corte Suprema, el juez Rehnquist, falleció. El Presidente George W. Bush llenó estas nuevas vacantes con el juez Samuel A. Alito y el Presidente de la Corte Suprema John G. Roberts.

Sin embargo, la evolución del derecho al aborto desde Roe ha sido guiada también por otros factores además de por el cambio de rostros en la magistratura. Es posible vislumbrar en esta evolución intentos por parte de varios miembros de la Corte Suprema de reconciliar lo aparentemente irreconciliable, de encontrar un término medio que pudiese satisfacer al menos a algunas de las partes contendientes que han buscado influir en el tratamiento brindado por la Corte Suprema al tema del aborto. Diferentes jueces se han esforzado denodadamente al respecto. Cuán exitosos han sido será discutido más adelante. Antes de llegar a este punto, comienzo con un bosquejo de la evo-

4505 U.S. 833 (1992). 
lución histórica del derecho al aborto y con un examen de los asuntos jurídicos que están en juego en la controversia sobre el aborto.

\section{HISTORIA DEL DERECHO CONSTITUCIONAL A ABORTAR}

Existe un importante aspecto en el cual el debate en la Corte Suprema acerca de la protección constitucional del derecho a abortar está desconectado del debate público sobre el aborto. Las consignas y carteles en las manifestaciones frente a las clínicas que practican abortos, en las reuniones a favor o en contra de Roe, y en gran parte de la discusión en los medios de comunicación, podrían razonablemente llevar a alguien a suponer que el problema central en discusión es si el feto es una persona o no. K. LUKER está seguramente en lo cierto cuando dice que el debate público acerca del aborto es fundamentalmente «un debate acerca de los que nos hace personas» $»^{5, *}$. De hecho, ningún juez de la Corte Suprema ha estado jamás comprometido con la posición de que la Constitución debería considerar al feto como una persona, y si la Corte Suprema llegase alguna vez a adoptarla las implicaciones serían mucho más radicales de lo que, incluso los más fervientes opositores a Roe parecen ser conscientes ${ }^{6}$. A decir verdad, los contendientes de ambos bandos en la disputa sobre el aborto han evitado proponer aún el argumento de que los métodos abortivos deberían minimizar cualquier dolor experimentado por el feto. Los contendientes pro elección temen, quizás, que esto sea una pendiente resbaladiza hacia la concesión de que el feto es una persona. Esto no necesariamente es verdadero, como indica el hecho de que aceptemos leyes que prescriban un modo humano de matar animales sin por ello concederles a los animales derechos legales. Por la otra parte, no es claro que los métodos abortivos que los contendientes pro vida encuentran más objetables - tales como el aborto por nacimiento parcialprovoquen más dolor que métodos abortivos alternativos.

Si la Corte Suprema fuese a dictaminar que un feto es una persona jurídica dentro del significado de la Decimocuarta Enmienda de la Constitución de los Estados Unidos, esto bien podría traer consigo la obligación de proscribir el aborto como una cuestión de derecho constitucional federal —al menos en una amplia gama de circunstan-

${ }^{5}$ LuKER, 1984: Abortion and the Politics of Motherhood, Los Ángeles: University of California Press, p. 5.

* N. del T.: En el texto original se utiliza la palabra inglesa personhood. No existe una traducción directa al castellano para este término que designa al conjunto de propiedades que nos hacen una persona. Aunque a veces se utiliza el neologismo «personidad» para traducirlo, hemos preferido evitarlo.

${ }^{6} \mathrm{~J}$. J. THOMPSON ha, célebremente, argumentado en contra de la percepción común respecto a que si uno esta a favor del aborto o no, depende de si uno piensa que el feto es una persona o no. Esta autora argumenta que si una mujer un día despertase y descubriese que un brillante violinista enfermo ha sido conectado mediante tubos a sus riñones y que la conexión debe ser mantenida por nueve meses, para que el violinista no muera, dicha mujer no tendría ninguna obligación moral de mantener la conexión en contra de su voluntad [«A Defense of Abortion», Philosophy and Public Affairs, vol. 1, n. ${ }^{\circ} 1$ (Fall 1971), pp. 47-66]. R. DworkIN puntualiza que el argumento de THOMPSON, aunque influyente entre los filósofos, no permite zanjar la cuestión en el ámbito jurídico porque «el aborto generalmente requiere un ataque físico contra el feto, no sólo dejar de auxiliarlo y, en cualquier caso, los padres inevitablemente son ubicados como una excepción a la doctrina general (que sostiene que uno en general no tiene un deber legal positivo de salvar a extraños) porque ellos tienen un deber legal de cuidar de sus hijos» [Life's Dominion: An Argument about Abortion, Eutanasia, and Individual Freedom, New Cork: Knopf, 1993, p. 111]. Para una discusión más elaborada de las implicaciones legales del argumento de THOmPSON, véase D. REgAn, 1979: «Rewriting Roe vs. Wade», Michigan Law Review, vol. 77, n. ${ }^{\circ}$, pp. 1569-1646. 
cias-. Los jueces y analistas jurídicos que argumentan que la decisión en Roe es inconstitucional y que debería ser revocada no son partidarios de esta visión ${ }^{7}$. Más bien, ellos son partidarios de restaurar el statu quo ante que existía previamente a que Roe se dictase, cuando la legislación referida al aborto era regulada de modo diferente en diferentes Estados - algunas veces por las legislaturas estatales y algunas veces como una cuestión de Derecho constitucional estatal-. Este statu quo ante había sido muy variado, yendo desde Estados liberales como Nueva York, que habían permitido el aborto, hasta Estados como Texas, que tenía prohibiciones absolutas, pasando por diversos regímenes regulativos intermedios ${ }^{8}$. La oposición a Roe por parte de jueces tales como Rehnquist, White, Scalia y Thomas no es, en consecuencia, necesariamente equivalente a la oposición al derecho a abortar como tal. Más bien, es una oposición a federalizar el problema del derecho al aborto como una cuestión de Derecho constitucional ${ }^{9}$.

La idea de que el gobierno debería regular o limitar el acceso de las mujeres al aborto para proteger al feto es relativamente reciente en el Derecho y en la política estadounidense. Históricamente su aparición parece haber estado ligada al incremento de abortos practicados por mujeres blancas, protestantes, casadas de clase media y alta (como opuestas a las mujeres de otras razas, de bajos ingresos y solteras) entre mediados y fines del siglo XIX, y a la amenaza al orden social existente que estos nuevos acontecimientos implicaban ${ }^{10}$. Antes que esto sucediese, el aborto había sido regulado, pero el argumento a favor de la regulación era que ésta protegía la salud de la madre. El aborto era un procedimiento peligroso que frecuentemente conducía a infecciones y a la muerte. Sin embargo, como el juez Blackmun observó en su voto por la mayoría en Roe, en 1973 los adelantos médicos eran tales que estadísticamente una mujer corría mayor riesgo médico si cargaba con el niño hasta el término del embarazo que si tenía un aborto temprano ${ }^{11}$.

Esta realidad modificada estableció el contexto para el análisis de la Corte Suprema del derecho al aborto en Roe, en el que una ley de Texas que había transformado en un delito «practicar un aborto» a menos que la vida de la madre estuviese amenazada por la continuación del embarazo, fue declarada inconstitucional. Por razones que serán exploradas más adelante, se sostuvo que tales leyes violaban la Cláusula del Pro-

\footnotetext{
${ }^{7}$ Véase, por ejemplo, el voto en disidencia del juez Rehnquist en Roe, en el que concede que tiene «pocas dudas» respecto a que leyes proscribiendo el aborto en cualquier circunstancia no sobrevivirían a un examen constitucional [410 U.S. 113, en p. 173 (1973)].

${ }^{8}$ Debería advertirse que antes de Roe ningún Estado de Estados Unidos había considerado nunca al feto como una persona jurídica. Tal como puntualiza R. DwORKIN, aun Estados con las más restrictivas leyes anti aborto no castigaban al aborto tan severamente como el homicidio, lo cual deberían haber hecho de haber pensado que el feto era considerado por la Constitución como persona, ni tampoco intentaban evitar que las mujeres procurasen abortar en jurisdicciones donde el aborto era legal, «The Great Abortion Case», p. 50.

9 Esto deja abierta la pregunta respecto a qué podrían hacer otras ramas del gobierno federal. El enfoque a la legislación sobre el aborto centrado en los Estados fue de alguna manera socavado por la Ley de Prohibición del Aborto por Nacimiento Parcial, la cual fue convertida en ley por el Presidente George W. Bush en noviembre del 2003, y que es discutida más tarde en el texto. Pero nada en esta legislación, o en la defensa que de ella hizo la Corte en el 2007 en Gonzales vs. Carhart 127 S. Ct. 1610 (2007), plantea una cuestión vinculada con la Cláusula de Supremacía más allá de la proscripción de este poco común procedimiento abortivo.

${ }^{10}$ Véase J. MoHR, 1978: Abortion in America: The Origins and Evolution of National Policy, Oxford: Oxford University Press, especialmente los caps. 3 y 4.

${ }^{11} 410$ U.S. 113 (1973), en p. 149.
} 
ceso con todas las garantías de la Enmienda Decimocuarta ${ }^{12}$. Primero vamos a clarificar el bolding*. El voto por la mayoría del juez Blackmun trata al aborto de modo diferente durante los tres trimestres de un embarazo normal:

a) Durante el estadio anterior a aproximadamente el fin del primer trimestre, la decisión de abortar y su realización debe dejarse al criterio del médico de cabecera de la mujer embarazada.

b) Durante el estadio siguiente a aproximadamente el fin del primer trimestre, el Estado, en la promoción de su interés por la salud de la madre, puede, si elige hacerlo, regular el procedimiento abortivo en modos que estén razonablemente relacionados con la salud maternal.

c) Durante el estadio siguiente a la viabilidad, el Estado, en la promoción de su interés en la potencialidad de vida humana, puede, si elige hacerlo, regular, y hasta prohibir, el aborto excepto cuando es necesario, de acuerdo a un apropiado criterio médico, para la preservación de la vida o la salud de la madre ${ }^{13}$.

Este test basado en trimestres limitó enormemente la facultad de los Estados para regular el aborto. Antes de finalizar el primer trimestre, el aborto no podría ya ser regulado en absoluto; antes del momento de viabilidad, podría ser regulado sólo en beneficio de la salud de la madre; y aun después de la viabilidad, si un Estado opta por regular o prohibir el aborto actuando en función de su interés «en la potencialidad de la vida humana», éste podría ser derrotado si el médico de cabecera de la madre hiciese un juicio «apropiado» señalando que abortar fuese necesario para su «vida o salud».

En Roe, la Corte Suprema reconoció que el Estado tiene un interés en la vida humana potencial, pero la Corte Suprema circunscribió aquel derecho y en efecto lo subordinó al derecho de la mujer a abortar, aun (con algunas exigencias) después del momento de viabilidad. En los años subsiguientes a Roe, distintas modificaciones al derecho constitucional que este creó fueron agregadas por la cambiante mayoría en la Corte Suprema.

En ciertos aspectos, el derecho reconocido en Roe fue protegido y expandido. En Doe vs. Bolton ${ }^{14}$, también dictada en 1973, la Corte Suprema dejó sin efecto las restricciones que pesaban sobre los lugares que podían ser utilizados para practicar abortos, dando lugar a las modernas clínicas de abortos. Tres años más tarde, en Planned Parenthood of Central Missouri vs. Danforth ${ }^{15}$, la Corte Suprema denegó a los Estados la facultad para conceder a los maridos poder de veto sobre la decisión de sus esposas de abortar embarazos, y también sostuvo que a los padres de niñas menores solteras no se les podía conceder un veto absoluto sobre los abortos. En 1979, en Colautti vs. Franklin ${ }^{16}$, declaró su intención de conceder a los médicos amplia discreción para de-

${ }^{12}$ La Cláusula del Proceso con todas las garantías establece: «Ningún Estado [...] privará a ninguna persona de la vida, la libertad, o la propiedad, sin un debido procedimiento legal».

* N. del T.: Hemos optado por no traducir este término ya que en los sistemas de Derecho continental no existe otro equivalente. El mismo puede ser entendido como la ratio decidendi del caso, las consideraciones esenciales de la decisión jurídica que fundamentan lo resuelto.

13410 U.S. 113 (1973), en pp. 164-165.

14410 U.S. 179 (1973).

15428 U.S. 476 (1976).

16439 U.S. 379 (1979). 
terminar cuándo un feto puede vivir fuera del seno materno. Los jueces dijeron que aunque un Estado puede buscar proteger a un feto viable, la determinación de viabilidad debe dejarse a los doctores. En 1983, la Corte Suprema estableció límites adicionales a los tipos de regulaciones que los Estados pueden establecer sobre el aborto. En un trío de decisiones, City of Akron vs. Akron Center for Reproductive Health ${ }^{17}$, Planned Parenthood Association of Kansas City, Missouri vs. Ashcroft ${ }^{18}$, y Simopoulos vs. Virginia ${ }^{19}$, por una votación de seis contra tres, la mayoría de la Corte Suprema negó a los Estados y a las comunidades locales la facultad de exigir que las mujeres con más de tres meses de embarazo aborten en un hospital y dejó sin efecto las regulaciones que, entre otras cosas, imponían un periodo de espera de veinticuatro horas entre la firma del formulario de consentimiento para el aborto y el procedimiento médico. Tres años más tarde (esta vez por una votación de cinco contra cuatro, que reflejaba el giro conservador de la Corte Suprema que para entonces ya había comenzado) una mayoría simple dejó sin efecto las regulaciones de Pennsylvania que habían exigido a los doctores informar a las mujeres que desean que se les practique un aborto sobre los riesgos potenciales y sobre las facilidades disponibles para el cuidado prenatal y para el parto ${ }^{20}$. En 1987, los jueces se dividieron cuatro contra cuatro en Hartigan vs. Zbaraz ${ }^{21}$, dejando en consecuencia en pie una decisión de un tribunal inferior que invalidaba una ley de Illinois que podría haber restringido el acceso de algunas adolescentes al aborto.

A pesar del desarrollo y profundización del derecho constitucional de la mujer al aborto llevadas a cabo por estas decisiones, la Corte Suprema había comenzado también a limitar este derecho en diversos modos mucho antes de que la mayoría que sustentó Roe comenzara a erosionarse. Un área importante de restricción se refirió al financiamiento de los abortos. En 1977, la Corte Suprema estableció, en Maher vs. Roe ${ }^{22}$, que los Estados no tenían una obligación constitucional de pagar por abortos «no-terapéuticos», y tres años más tarde, una mayoría de cinco contra cuatro sostuvo, en $\mathrm{Ha}$ rris vs. McRae ${ }^{23}$, que aun cuando se trate de abortos médicamente necesarios que las mujeres buscan practicarse por su bienestar, ni los Estados ni el gobierno federal se encuentran bajo ninguna obligación constitucional de proveer financiamiento público. En 1979, en la primera de lo que iba a resultar ser una serie de decisiones regulando los derechos al aborto de las menores de edad que se encuentran bajo la custodia de sus padres, una mayoría de ocho contra uno en la Corte Suprema sostuvo en Belloti vs. Baird ${ }^{24}$ que los Estados pueden exigir que una embarazada menor de edad y soltera obtenga el consentimiento de sus padres para el aborto siempre y cuando el Estado establezca un procedimiento alternativo a la obtención de tal consentimiento, tal como el de permitir a la menor requerir la autorización del juez en lugar del consentimiento de sus padres. En 1981, una mayoría de seis contra tres sostuvo, en H. L. vs. Matheson ${ }^{25}$,

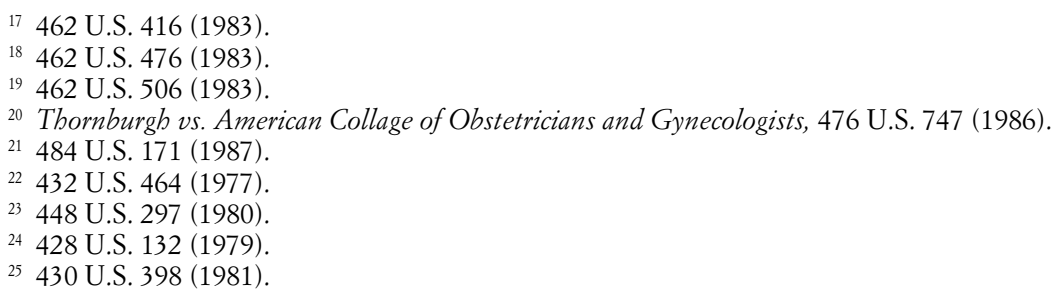


que los Estados pueden exigir a los médicos consultados por algunas niñas que todavía estén bajo la custodia de sus padres y sean demasiado «inmaduras» para decidir tales cuestiones por ellas mismas, que traten de dar noticia a los padres antes de practicarles un aborto. Dos decisiones de 1990, Hodgson vs. Minnesota ${ }^{26}$ y Obio vs. Akron Center for Reproductive Healtb ${ }^{27}$, desarrollaron más las normas de notificación a los padres. En el caso Obio, una mayoría de seis contra tres respaldó una ley estatal requiriendo la notificación de al menos uno de los padres en tanto establecía una vía alternativa judicial, aunque en el caso Minnesota una mayoría de cinco contra cuatro dejó claro que leyes exigiendo que ambos padres sean informados antes de que una menor pueda practicar un aborto no sobrevivirían en el futuro.

En la época de las decisiones de 1990, gran parte del razonamiento subyacente a Roe había sido comprometido por la crucial decisión en Webster vs. Reproductive Health Services ${ }^{28}$ adoptada once meses antes por una Corte Suprema múltiplemente dividida. Con esta decisión, el sustento mayoritario en la Corte Suprema a favor de Roe parecía finalmente haberse evaporado - tal como el juez Blackmun reconocía en un amargo voto en disidencia-. En su opinión dominante, la Corte Suprema del caso Webster respaldaba una ley de Missouri que exigía que antes de que un médico realizase un aborto a una mujer, de quien tenía razones para creer que estaba embarazada de veinte o más semanas, debía determinar si el feto era viable. Más importante que esta nueva restricción comparativamente menor al derecho de una mujer a un aborto, fue que la mayoría lanzó un ataque frontal sobre la estructura de análisis basada en trimestres de Roe, la cual había sido parte del derecho durante la década y media precedente.

La observación incidentalmente realizada por el juez Blackmun en Roe según la cual el Estado tiene un interés en «la vida humana potencial» había regresado para atormentarlo. En manos del Presidente de la Corte Suprema, el juez Rehnquist, se transformó en una estaca que él parecía dispuesto a clavar en el corazón de Roe. En un voto firmado también por los jueces Kennedy y White, Rehnquist rechazaba de plano el «rígido» esquema de Roe como «difícilmente consistente con la idea de una Constitución configurada con términos generales, como está la nuestra, y expresándose por lo general en principios generales». Rehnquist continuaba diciendo que la mayoría «no veía por qué el interés del Estado en proteger la vida potencial debería comenzar a existir recién a partir del momento de viabilidad, ni que debería existir, en consecuencia, una línea rígida permitiendo la regulación estatal después del momento de viabilidad pero prohibiéndola antes del mismo» ${ }^{29}$.

La jueza O'Connor había anunciado su oposición al esquema trimestral de Roe mucho antes ya, en $1985^{30}$ y la única objeción del juez Scalia a la mayoría en Webster era que debería haber ido más lejos y haber hecho explícito lo que, según él insistía, habían hecho implícitamente, a saber, revocar Roe. Esto parecía indicar que ahora existían cinco votos a favor de revocar Roe, aun si los cinco jueces en cuestión no estaban

\footnotetext{
26497 U.S. 417 (1990).

27497 U.S. 502 (1990).

28492 U.S. 490 (1989).

29492 U.S. 490 (1989), en pp. 518-519.

${ }_{30}$ Véase su opinión en disidencia en Thornburgh vs. American College of Obstetricians and Gynecologists,
} 476 U.S. 747 (1985), en p. 828. 
todavía preparados para alcanzar aquel extremo en la medida que la ley de Missouri en cuestión, de hecho, no intentaba regular los abortos previos a la viabilidad. El principio había sido admitido, aun cuando lo que Scalia descalificaba como la «sobriedad recientemente contraída» por la Corte Suprema significaba que «la mansión de la constitucionalizada normativa jurídica referida al aborto, construida apresuradamente en Roe vs. Wade, debe ser desmantelada parte por parte» ${ }^{31}$. No más convencido que Scalia por lo que él veía como «un autocontrol fingido» por parte de la mayoría, el juez Blackmun, escribiendo el voto en disidencia (también por Brennan y Marshall), declaraba que la decisión mayoritaria «implícitamente invita a cualquier legislatura estatal a dictar más y más regulaciones restrictivas del aborto para provocar que más y más casos hayan de estar sometidos a examen, con la esperanza de que alguna vez, al final, la Corte Suprema haga que el derecho referido a la libertad procreativa regrese a las severas limitaciones que por lo general prevalecían en este país antes del 22 de junio de 1973». Blackmun concluía: «De este modo, "sin pena ni gloria” * los votantes por la mayoría acaban por descontar un caso que constituyó un hito fundamental para la última generación, ensombreciendo así las esperanzas y anhelos de todas y cada una de las mujeres de este país que habían llegado a creer que la Constitución garantizaba su derecho a ejercitar algún control sobre su capacidad única de sacar adelante un embarazo» ${ }^{32}$.

Que algunas de las propias formulaciones de Blackmun en Roe puedan ser usadas para socavar su resultado en Webster es característico de la manera fortuita en que la interpretación constitucional a menudo evoluciona en el tiempo. Quizás este mismo hecho debería haber alertado a Blackmun de la posibilidad de que quizá no todo estuviera perdido desde su punto de vista. Aunque el esquema trimestral de Roe había sido echado por la borda y una mayoría en la Corte Suprema había abrazado la idea de que el Estado puede afirmar un interés en proteger la vida humana «potencial» aun antes del punto en el cual un feto es viable, esto no necesariamente significaba que la protección constitucional del derecho de la mujer al aborto en breve acabaría, junto al esquema trimestral, en los anales de la historia constitucional. Ahora todo giraría en torno a cuál resulta ser la naturaleza del interés estatal en la vida potencial. Hasta que esto no fuese determinado, cuál sería el impacto de Webster sobre el derecho constitucionalmente protegido de la mujer al aborto simplemente no podría ser conocido. Esto permanecería poco claro durante casi tres años.

En retrospectiva, podemos decir que había indicios que existían desde la década de los setenta. En Maher vs. Roe (1977), la Corte Suprema había declarado que el derecho reconocido en Roe «protege a la mujer de interferencias indebidamente gravosas con su libertad para decidir si termina con su embarazo» ${ }^{33}$. Esta noción de que la interferencia estatal con el derecho de la mujer al aborto no debe ser «indebidamente gravosa» había aparecido primero en Belloti vs. Baird, en el cual la Corte Suprema había sostenido que los Estados no pueden «imponer cargas indebidas sobre una menor capaz de prestar un consentimiento informado» ${ }^{34}$. Desde ese momento, varios miembros

31492 U.S. 490, en p. 537.

* N. del T.: Hemos optado por esta expresión para traducir la expresión inglesa «not with a bang, but a whimper».

${ }^{32}$ Ibidem, en pp. 538, 557

33 Mahervs. Roe, 432 U.S. 464, en pp. 473-474 (1977).

${ }^{34}$ Bellotivs. Baird I, 428 U.S. 132, 147 (1976). 
de la Corte Suprema, inclusive varias mayorías, habían sostenido que ningún Estado puede «indebidamente gravar el derecho de una mujer a que se le practique un aborto» ${ }^{35}$, que el derecho constitucional afirmado en Roe «protege a la mujer de interferencias indebidamente gravosas con su libertad para decidir si termina con su embarazo» ${ }^{36}$, que las exigencias de consentimiento informado para los abortos en el primer trimestre serán mantenidas si no «gravan indebidamente el derecho de una mujer a que se le practique un aborto» ${ }^{37}$, y que el interés estatal en proteger la vida humana «no resulta por lo menos hasta el tercer trimestre, lo suficientemente apremiante como para justificar una interferencia estatal indebidamente gravosa... $>^{38}$. En 1983, la jueza O'Connor dejó claro en su voto en disidencia en City of Akron vs. Akron Center for Reproductive Health que, al menos para ella, la cuestión del aborto giraba en torno a encontrar restricciones que no «infrinjan sustancialmente» o impongan interferencias «indebidamente gravosas» sobre el derecho de la mujer a un aborto ${ }^{39}$, una opinión que ella reafirmó en Hodgson vs. Minnesota (1990) como parte del argumento para mostrar que sólo cuando la regulación estatal impone una «carga indebida» sobre la capacidad de una mujer para tomar la decisión de abortar, el poder del Estado penetra en el corazón de la libertad protegida por la Cláusula del Proceso con todas las garantías [Due Process Clause $]^{40}$.

A la vista de estas formulaciones, no debió resultar sorprendente que los jueces O'Connor y Kennedy — quienes habían declinado la invitación del juez Scalia para revocar Roe en Webster - fuesen parte de un bloque de centro en la Corte Suprema (siendo el otro miembro Souter) comprometido con la reformulación del derecho constitucional al aborto por referencia a un estándar de «cargas indebidas» enraizado en la cláusula del proceso con todas las garantías de la Enmienda Decimocuarta. Este fue el paso dado en Planned Parenthood of Southeastern Pennsylvania vs. Casey, dictado en junio de 1992, en el cual una Corte Suprema, una vez más, múltiplemente dividida, reafirmó el holding básico de Roe, a la vez separándolo del esquema de análisis basado en trimestres ahora en desuso y vinculándolo en cambio a la noción de cargas indebidas ${ }^{41}$. La decisión Casey dejó muchas cuestiones sin resolver. Efectivamente, como veremos, esto creó nuevas áreas de incertidumbre en el derecho constitucional del aborto. Pero dos cuestiones fundamentales sobre las que Webster había generado considerable confusión estaban ahora aclaradas. La primera era que «el holding esencial de Roe vs. Wade debería ser mantenido y una vez más reafirmado» ${ }^{42}$. Esto significaba no sólo que la Constitución garantiza a las mujeres el derecho a abortar que ninguna legislatura tiene el poder de destruir, sino también que la Corte Suprema decidía no rechazar completamente el razonamiento original de Blackmun que había situado la protección constitucional en cuestión en el derecho a la intimidad entendido como derecho derivado de la Cláusula del Proceso con todas las garantías. Éste fue un desarrollo notable, porque el razonamiento de Blackmun había sido muy criticado en la

\footnotetext{
35 Belloti vs. Baird II, 433 U.S. 622, 640 (1979).

${ }^{36}$ Mahervs. Roe, 432 U.S. 464, en pp. 473-474 (1977).

37 Belloti vs. Baird I, 428 U.S. 132, 147 (1976).

38 Beal vs. Doe, 432 U.S. $438-46$ (1977).

39462 U.S. 416, en pp. 461-2 (1983).

40497 U.S. 417, en pp. 458-9 (1990).

41505 U.S. 833 (1992).

42 Ibídem, p. 2796.
} 
literatura académica, y muchos de los más recientemente nombrados miembros de la Corte Suprema - por no mencionar al Presidente de la Corte Suprema, Rehnquisthabían abiertamente manifestado no estar nada convencidos del mismo. Ésta fue quizás la razón principal por la que muchos pensaron en Webster como el principio del fin de Roe, impulsando la introducción de legislación para revertir Webster en el Congreso y convirtiendo al aborto en una cuestión política que atrajera sobre sí toda la atención en la carrera para las elecciones presidenciales de 1992.

Como resultado, declarando que «[la] libertad no encuentra protección en una jurisprudencia errática» ${ }^{43}$, la mayoría simple invocó la doctrina del stare decisis. Esta doctrina descansa en la idea de que «ningún sistema judicial podría hacer su trabajo en la sociedad si considerara desde cero cada cuestión en todos y cada uno de los casos en que aparece» y, consecuentemente, una vez que una decisión pasa a formar parte del Derecho en el cual la gente ha llegado a confiar, no debería ser derribada a la ligera. El stare decisis no es un «mandato inexorable» que obligue a ver como vinculante todo precedente, y podría ser razonablemente ignorado si una regla se ha «presentado como intolerable simplemente por desafiar la viabilidad practica», si es «objeto de una especie de confianza que conferiría un carácter especialmente dificultoso a las consecuencias de revocarla y agregaría inequidad a los costos del rechazo», o si «los hechos han cambiado tanto o llegan a ser vistos de modo tan diferente, como para haberle quitado de modo significativo a la antigua regla aplicación o justificación» ${ }^{44}$. Pero la mayoría simple sostuvo que ninguna de estas consideraciones se aplicaban en el caso de Roe, por eso éste debería seguir siendo vinculante, sin que «sea necesario decir que cada uno de nosotros de haber sido miembros de la Corte Suprema cuando la valoración de los intereses del Estado (en proteger la vida potencial) llegó ante ella como una cuestión nueva, hubiéra concluido, como la Corte Suprema de Roe lo hizo, que su peso es insuficiente para justificar una prohibición sobre los abortos realizados antes de la viabilidad aun cuando esté sujeta a ciertas excepciones» ${ }^{45}$. Apelando a este razonamiento, la mayoría simple en Casey sostuvo que una mujer tiene un derecho protegido constitucionalmente a que se le practique un aborto hasta el momento de la viabilidad del feto, y después de ese momento, los Estados tienen el poder para «restringir los abortos», siempre que la ley contenga «excepciones para los embarazos que hacen peligrar la vida o la salud de la mujer» ${ }^{46}$.

La segunda cuestión resuelta por la decisión adoptada en Casey era que el interés estatal en proteger la vida potencial habría de ser visto como subordinado al derecho constitucionalmente protegido de la mujer al aborto. La discusión de la mayoría simple sobre este punto no equivalía a una explicación definitiva de la naturaleza del interés estatal o del interés de la mujer, pero fijó algunos límites sobre lo que pueden hacer los Estados en la regulación del aborto. Superado el momento de la viabilidad, las amenazas a la vida o a la salud de la mujer pueden triunfar sobre las legítimas restricciones al aborto enraizadas en el interés estatal en proteger la vida potencial. Dependiendo de cuán extensamente se defina «salud» (en particular si se incluye el bienestar psicológi-

\footnotetext{
${ }^{43}$ Ibidem, p. 2803.

${ }^{44}$ Ibidem, pp. 2808-2809.

${ }^{45}$ Ibidem, p. 2817.

46 Ibidem, p. 2791.
} 
co), y teniendo en cuenta que generalmente será un médico elegido por la paciente quien decida si la salud de la mujer se encuentra amenazada, esto podría llegar a resultar un obstáculo sustancial al poder del Estado aún más allá del momento de la viabilidad.

La decisión de Casey significaba un rechazo a la lógica subyacente a Roe, no sólo porque fue abandonado explícitamente el análisis basado en trimestres, sino también porque se sostuvo inequívocamente que el interés del Estado en la vida potencial empieza después del momento en el cual el feto es viable. El interés estatal es visto como dotado de mayor fuerza a medida que el feto se desarrolla, justificando el aumento gradual de la interferencia del Estado con los derechos constitucionalmente protegidos de las mujeres embarazadas sobre el curso de sus embarazos. Antes del momento de la viabilidad, el test de la «carga indebida» de la Corte Suprema excluye «normas sanitarias [in]necesarias que tienen el propósito o el efecto de presentar un obstáculo sustancial a la voluntad de una mujer de que se le practique un aborto» ${ }^{47}$. Pero esto no significa que el Estado no tenga poder para tratar de influenciar la decisión de abortar de una mujer durante los estadios tempranos del embarazo. «Lo que está en juego» insistía la mayoría simple en Casey, «es el derecho de la mujer a tomar la última decisión, no el derecho a ser aislada de los demás al adoptarla» ${ }^{48}$. En el comienzo del embarazo, el Estado «puede promulgar leyes y decretos diseñados para informar (a la mujer) acerca de cuáles son los argumentos sociales y filosóficos de gran peso que se pueden aducir en apoyo de la continuación del embarazo» ${ }^{49}$. En la medida en que las regulaciones en cuestión no tengan el propósito ni el efecto de colocar una «carga indebida» sobre las mujeres al imponerles un «obstáculo sustancial» sobre sus decisiones a favor del aborto, el Estado puede tratar de lograr que las mujeres reflexionen sobre esa decisión y alentarlas a considerar otras alternativas ${ }^{50}$.

Precisamente qué habría de considerarse como una carga indebida en determinados casos no estaba de ningún modo claro y era seguro que provocaría posteriores litigios, tal como los disidentes en Casey advirtieron rápidamente. En la misma sentencia de Casey, la Corte Suprema sostuvo que una ley de Pennsylvania colocaba una carga indebida sobre las mujeres en tanto que exigía a una mujer casada que había decidido abortar firmar una declaración de que había notificado a su esposo, pero que, sin embargo, otras diversas disposiciones de esa ley de Pennsylvania podrían superar el test. Éstas incluían disposiciones diseñadas para asegurar que la mujer presentara su consentimiento informado al procedimiento, al requerir que reciba determinada información como mínimo veinticuatro horas antes de someterse al procedimiento abortivo, que en el caso de una menor, debe existir el consentimiento informado de por lo menos uno de los padres como mínimo veinticuatro horas antes del procedimiento (con un procedimiento judicial alternativo previsto), y que las clínicas donde se realicen abortos puedan ser obligadas a cumplir con diversas exigencias de información. La exigencia de notificación al esposo fue entendida como diferente de las demás en la medida en que aunque la mayoría de las mujeres contarían voluntariamente a sus esposos cuáles eran sus intenciones, las mujeres que son víctimas de abuso físico y psicológico

\footnotetext{
47 Ibidem, p. 2821.

${ }^{48}$ Ibidem.

49 Ibidem, p. 2818.

${ }^{50}$ Ibidem.
} 
por parte de ellos «pueden tener muy buenas razones para no desear informar a sus esposos su decisión de que se les practique un aborto» ${ }^{51}$. Si la Corte Suprema fue clara en que esto inclinaba la balanza de las cargas indebidas mientras que el periodo de espera de veinticuatro horas no lo hacía, el razonamiento detrás de dicha distinción no era del todo comprensible. En particular, la Corte Suprema parecía haber combinado las muy diferentes preocupaciones de, por un lado, tratar de asegurar que la mujer tome una decisión bien meditada (en el sentido de no ser una decisión de la cual ella pudiera más tarde llegar a arrepentirse) y, por otro, el derecho del Estado a promover su interés en la vida potencial al regular la elección de abortar de una mujer. Por éstas y otras razones, Casey planteaba tantas preguntas como respuestas brindaba, algo que los posteriores litigios comenzaron pronto a revelar ${ }^{52}$.

Durante los siguientes ocho, años la Corte Suprema se mantuvo en silencio sobre el problema del aborto, aparentemente satisfecha con el hecho de esperar que bajo el nuevo ordenamiento, los litigios se agotasen en las instancias inferiores. Luego los jueces de la Corte Suprema revisaron el tema en Stenberg vs. Carbart, centrándose en el intensamente cuestionado procedimiento llamado por sus críticos «aborto por nacimiento parcial». Este procedimiento, relativamente inusual, fue definido por la ley de Nebraska que lo vedaba, como «extraer intencionalmente de la vagina un niño vivo nonacido, o una porción sustancial del mismo, con el propósito de realizar un procedimiento que los [abortistas] saben que matará al [...] niño y de hecho [...] lo hace» ${ }^{53}$. Leyes similares habían sido promulgadas en treinta legislaturas estatales. La cuestionada ley de Nebraska convirtió en delito practicar un aborto por nacimiento parcial a menos que fuera necesario para salvar la vida de la madre. La condena llevaría al revocamiento automático de la licencia del médico para ejercer su profesión. La Corte de Apelaciones del Octavo Distrito había confirmado la conclusión de la corte de distrito respecto a que la ley era inconstitucional, y la Corte Suprema reafirmó este resultado en una disputada decisión de cinco contra cuatro.

El juez Kennedy, quien había sido parte de la mayoría en Casey, votó ahora con los disidentes ${ }^{54}$. La jueza O'Connor, la arquitecta principal del test de la carga indebida de Casey, dejó claro que aunque estaba votando para declarar inconstitucional la cuestionada ley de Nebraska, lo hacía porque era excesivamente amplia y carecía de una excepción para el caso de que se viera afectada (además de la vida) de la madre. De otra manera, la habría mantenido como constitucional, lo cual, dada la posición de Kennedy, sugería que la mayoría de cinco contra cuatro en la Corte Suprema podría estar dispuesta a respaldar una ley más restrictiva del aborto por nacimiento parcial con una excepción por razón de la afectación de la salud de la madre. Mucho dependía, por lo tanto, de por qué la mayoría entendía la ley de Nebraska demasiado inclusiva, y de exactamente qué sería necesario para asegurar la protección de la salud de la madre.

\footnotetext{
${ }^{51}$ Ibidem, p. 2828.

52 Véase Fargo Women's Health Organization vs. Schafer, 113 S. Ct. 1668 (1993) y Planned Parenthood vs. Casey II, 114 S. Ct. 909 (1994).

53530 U.S. 914 , en p. 922 (2000).

54 Esto no afectó al resultado porque el juez White, quien había disentido en Casey, en el ínterin, había sido reemplazado por la jueza Ginsburg, quien refrendó la aplicación de Casey en Stenberg.
} 
Los dos temas son distintos. En Casey se había sostenido que antes de la viabilidad, las regulaciones sobre el aborto no deben poner cargas indebidas sobre el derecho de una mujer a abortar. La ley cuestionada podía ser interpretada de modo que incluyera «dilatación y evacuación» (D\&E), procedimientos comúnmente usados en abortos durante el segundo trimestre y previos a la viabilidad, así como también el inusual método «dilatación y extracción» (D\&X), típicamente usado después de las dieciséis semanas, cuya prohibición perseguía Nebraska ${ }^{55}$. Consecuentemente, la Corte Suprema aplicó el test de la carga indebida de Casey y encontró deficiente a la ley porque el método $\mathrm{D} \& \mathrm{E}$ es visto como más seguro que las alternativas disponibles para abortos anteriores a la viabilidad realizados entre las doce y veinte semanas de gestación. Ésta es la parte menos controvertida de la decisión pues Nebraska nunca buscó proscribir el procedimiento D\&E. La cuestión que dividía a la mayoría y a los disidentes, era si la Corte Suprema debería haber reconstruido de modo más estricto la ley para tornarla constitucional, o dejarla sin efecto y, en consecuencia, exigirle a Nebraska que promulgara una ley diseñada de un modo más estricto.

Los riesgos comparativos de los diferentes procedimientos abortivos también se encuentran en el centro de la parte más controvertida de la decisión, los que involucran al procedimiento D\&X. Esto se refiere a ciertos abortos tardíos donde el procedimiento $\mathrm{D} \& \mathrm{E}$ ya no es efectivo debido al mayor desarrollo del embarazo y por tratarse de casos de presentación podálica *. El doctor tira del cuerpo del feto a través del cuello del útero (de ahí el término «nacimiento parcial»), destruye el cráneo y extrae el feto a través del cuello del útero. Se alegó en juicio que este procedimiento era más seguro que otras alternativas para la mujer en circunstancias que involucran fetos inviables, para mujeres con cicatrices uterinas anteriores, o para quienes el parto inducido sería particularmente peligroso. Como resultado, la mayoría encontró que la falta de una excepción por razón de la afectación de la salud de la madre, volvía inconstitucional la ley de Nebraska.

Entre la mayoría y los disidentes se discutía el carácter de la prueba según la cual el procedimiento $\mathrm{D} \& \mathrm{X}$ es el método más seguro disponible en algunas circunstancias y por lo tanto debe ser protegido a través de una excepción que privilegie la salud de la madre. En Roe se había insistido en la inclusión de tal excepción cuando los Estados regulan los procedimientos abortivos, y en Casey se había afirmado que deben existir excepciones cuando el aborto es «necesario, según un apropiado juicio médico, para la preservación de la vida o de la salud de la madre» ${ }^{56}$. ¿Pero qué constituye un juicio médico apropiado? Roe había sido largamente criticado porque esta cláusula de escape creaba la posibilidad de un aborto a libre petición. «Apropiado juicio médico» había sido interpretado como el juicio del médico de cabecera, y siempre habría un médico dispuesto a decir que llevar un embarazo a término sería de algún modo dañino para la salud física o psicológica de la mujer. Parte de la oposición a Casey había derivado de su limitación a esta cláusula de escape al sostener que el Estado puede regular el aborto en tanto esto no implique una carga indebida sobre las mujeres. Los disi-

${ }^{55}$ El procedimiento D\&X es a veces nombrado como el procedimiento «D\&E indemne» aunque yo usaré aquí $\mathrm{D} \& \mathrm{X}$.

* N. del T.: Hemos optado por traducir la expresión inglesa «the fetus presents feet first» como «caso de presentación podálica» para hacer referencia a los casos en que por la postura, el feto no está cabeza abajo.

${ }^{56}$ Casey, 505 U.S. 883, en p. 879 (1992). 
dentes en Stenberg discrepaban unos con otros sobre si la regla de Casey debería haber sido adoptada. Sin embargo, coincidían en que Stenberg privaría de sentido a la regla de Casey porque la interpretación de «apropiado juicio médico» parecía ser lo suficientemente amplia como para posibilitar el aborto «a la carta» otorgando al médico de cabecera un veto sobre toda regulación del aborto.

La objeción aquí no era contra la proposición de que parte de la noción de carga indebida incluye la idea de que una mujer no debería ser obligada a padecer un procedimiento menos seguro cuando uno más seguro está disponible. Con independencia de cualquier otra cosa que pudiera significar, la carga indebida ha de incluir esta idea. Más bien la objeción se dirige hacia este interrogante: ¿quién debe decidir qué es seguro? El juez disidente Kennedy objetó que la mayoría había delegado esto al criterio de un médico de cabecera, posibilitando el aborto a pedido y así quitándole sentido a la modificación de Roe, hecha por Casey. La jueza Thomas agregó que la mayoría no probó que un «importante grupo» de opiniones médicas apoyara la afirmación de que el procedimiento D\&X es más seguro que las alternativas en cualquier circunstancia. ¿Bajo qué lógica o autoridad, se preguntó, debería la Corte Suprema descartar el criterio de la legislatura del Estado de Nebraska en esta cuestión fáctica y definir otro? Y «en una actitud de "te lo dije"», el juez Scalia insistió en que «aquellos que creen que sobre un asunto de política una votación de cinco a cuatro llevada a cabo por abogados no electos no debería prevalecer sobre el criterio de treinta legislaturas estatales tienen un problema, no con la aplicación de Casey, sino con su existencia misma. Casey debe ser revocado» ${ }^{57}$.

En 1994, los republicanos habían tomado el control de ambas cámaras del Congreso por primera vez en una generación. Esto llevó a la apertura de un nuevo frente en la batalla sobre el derecho al aborto en la política nacional. Habían existido escaramuzas incluso antes de que fuera dictada la sentencia de Stenberg, pero la decisión movilizó a las fuerzas pro vida para elaborar una prohibición nacional sobre el aborto por nacimiento parcial que fuera aceptable por la Corte Suprema. La Casa [Blanca] y el Senado habían sancionado prohibiciones sobre el aborto por nacimiento parcial en 1996 y 1997, pero éstas habían sido vetadas por el Presidente Clinton. Cuando George W. Bush asumió el cargo en enero de 2001, las estrellas se alinearon para promulgar una prohibición a nivel nacional. Esto ocurrió el 5 de noviembre de 2003, cuando el Presidente Bush firmó la Ley de prohibición del aborto por nacimiento parcial, la cual había sido sancionada en ley por ambas cámaras del Congreso.

La nueva ley federal se ocupó de ciertas debilidades que la Corte Suprema había identificado en la ley de Nebraska declarada inconstitucional en Stenberg. El Congreso respondió al problema de la excesiva amplitud excluyendo de manera explícita abortos D\&E como así también las extracciones $\mathrm{D} \& \mathrm{X}$ accidentales, en las cuales el médico terminaba realizando un aborto por nacimiento parcial inintencionado. Los políticos respondieron a la cuestión de la salud de la mujer llevando a cabo audiencias sobre la relativa seguridad del procedimiento D\&X y luego declarando en la ley que «existe consenso moral, médico y ético» respecto a que el aborto por nacimiento parcial «es un procedimiento atroz e inhumano que nunca es médicamente necesario y debería ser prohibido» ${ }^{58}$.

\footnotetext{
57 Stenberg vs. Carhart, 530 U.S. 914, en p. 955 (2000), cursivas en el original.

5818 U.S.C. $\$ \$ 11531$ (2000 ed., Supp. IV), p. 767.
} 
En los litigios que inevitablemente le siguieron, los tribunales federales inferiores revelaron que no estaban convencidos. La Ley de probibición del aborto por nacimiento parcial, fue revocada por los tribunales de distrito en California y Nebraska. Sus decisiones fueron ratificadas por los tribunales de apelación de los Circuitos Octavo y Noveno en 2005 y 2006. Pero la Corte Suprema concedió el certioriari, y en abril de 2007 adoptó una nueva decisión sosteniendo la constitucionalidad de la Ley de probibición del aborto por nacimiento parcial federal, revocando la decisión de los tribunales federales inferiores y revirtiendo así su propio precedente establecido siete años antes en Stenberg.

La nueva decisión Gonzales vs. Carhart, reflejó parcialmente los cambios en la conformación de la Corte Suprema ${ }^{59}$. La jueza O'Connor había anunciado su jubilación durante el verano de 2005, y el juez Rehnquist había muerto ese otoño, posibilitando al Presidente Bush su reemplazo por el Presidente de la Corte Suprema Roberts y el juez Alito. Ambos habían sido hábilmente imprecisos durante las audiencias de confirmación en el Senado acerca de sus opiniones sobre la constitucionalidad del aborto, pero eran bien conocidos como conservadores católicos y pocos observadores de la Corte Suprema quedaron sorprendidos cuando la mayoría de cinco contra cuatro que había sostenido la constitucionalidad del procedimiento D\&X en Stenberg fue reemplazada, en Gonzales, por una mayoría de cinco contra cuatro que tomó la visión opuesta.

El reemplazo del Presidente de la Corte Suprema Rehnquist por Roberts había dejado la aritmética de la Corte Suprema sobre el aborto intacta, sin embargo la jueza O'Connor había sido la autora tanto del test de la carga indebida de Casey, como del voto decisivo en su aplicación en Stenberg. El juez Alito, ahora unido al voto de la mayoría escrito por el juez Kennedy en la cual la Corte Suprema, sostuvo que el Congreso había resuelto el problema de la excesiva amplitud exceptuando el procedimiento D\&E y dejando indemnes a los médicos que realizaban accidentalmente procedimientos $\mathrm{D} \& \mathrm{X}$. Más aún, se sostuvo que la falta de una excepción por razón de la salud de la madre, había sido remediada por la determinación del Congreso acerca de que el procedimiento $\mathrm{D} \& \mathrm{X}$ nunca es médicamente necesario.

La base de la Corte Suprema para su deferencia hacia la determinación del Congreso no era del todo clara. Como lo señaló la jueza GiNSBURG en un mordaz disenso, los registros del Congreso estaban repletos de testimonios que contradecían la determinación de la ley en cuestión acerca de que el procedimiento $\mathrm{D} \& \mathrm{X}$ nunca era más seguro que las alternativas - por no mencionar evidencias de otras fuentes profesionales como el American College of Obstetricians and Gynecologists. La ley de un modo incorrecto afirma que ninguna facultad de medicina enseña el procedimiento $D \& X$, cuando de hecho muchas de las principales sí lo hacen. Más aún, como para subrayar la naturaleza superficial y sesgada de la audiencias, ninguno de los médicos que atestiguaron que el procedimiento $\mathrm{D} \& \mathrm{X}$ nunca es médicamente necesario lo había, de hecho, practicado $^{60}$. Las cortes federales tienen un largo historial negándose a ser deferentes hacia las determinaciones legislativas manifiestamente implausibles, y los tribunales inferiores siguieron ese precedente en este caso. Pero la nueva mayoría en la Corte Suprema

\footnotetext{
59 González vs. Carhart, 127 S. Ct. 1610 (2007).

60127 S. Ct. 1610, en p. 1643 (2007).
} 
no lo hizo, sosteniendo en cambio que frente al desacuerdo profesional sobre los méritos médicos del procedimiento, el Congreso era libre de tomar la posición que tomó.

\section{JURISPRUDENCIA SOBRE ABORTO}

Gran parte de la conmoción generada por la controversia acerca del aborto proviene de su rol simbólico en la política estadounidense; argumentos sobre «vida» versus «elección» sirven como representaciones de los conflictos sobre el rol de las mujeres en la sociedad estadounidense, el controvertido status de los valores «tradicionales» $\mathrm{y}$ «familiares», y el lugar de la religión en la política estadounidense ${ }^{61}$. Sin embargo, parte de esta conmoción ha sido generada internamente, por la manera en que Roe fue decidido y el argumento de la intimidad sobre el cual descansa. Esta controversia en parte proviene de la naturaleza demasiado radical del holding de Roe, y en parte del hecho de que el derecho a la intimidad sobre el cual el juez Blackmun basó su argumento no está explícitamente mencionado en la constitución.

Los argumentos acerca de la intimidad y la libertad reproductiva hunden sus raíces en la decisión de Griswold vs. Connecticut de la Corte Suprema adoptada en $1965^{62}$. Griswold fue la culminación de una batalla de cincuenta años para organizar una oposición formal a las leyes de control de natalidad ${ }^{63}$. Por una mayoría de siete contra dos, la Corte Suprema derribó una ley de 1879 que había tornado ilegal «el uso de cualquier droga o producto para evitar la concepción», sosteniendo que la relación marital está incluida en una esfera de intimidad, la cual pesa más que cualquier interés estatal legítimo en evitar la inmoralidad sexual ${ }^{64}$. Esta decisión proveyó parte de los fundamentos lógicos del razonamiento del juez Blackmun en Roe, en el cual sostuvo que la esfera de intimidad abarca decisiones relativas tanto al aborto como a la contracepción. Pero Griswold se aplicaba solamente a las parejas casadas; por sí mismo, esto no podía generar el derecho a la intimidad individual sobre el que Roe descansa. El argumento que sirvió como puente fue brindado en Eisenstadt vs. Baird en 1972 cuando el juez Brennan, escribiendo el voto de la mayoría, afirmó que en los casos de contracepción «el derecho a la intimidad si significa algo, es el derecho del individuo, soltero o casado, a no sufrir la intromisión del Gobierno en materias que afectan tan fundamentalmente a una persona como la decisión de engendrar o la de tener un hijo» ${ }^{65}$.

El resultado de Griswold ha sido a menudo criticado como una mediocre pieza de jurisprudencia constitucional y la extensión que Blackmun hace de ella a Roe nunca ha sido segura. La acusación más importante con la cual sus defensores han tenido que lidiar es que Griswold es señalado como un ejemplo de «legislación judicial» - que al dictarlo la Corte Suprema se erigió como una especie de superlegislativo. Existen dos posibles respuestas a esta línea de crítica para aquellos que apoyan el re-

${ }^{61}$ Un excelente tratamiento de la materia puede verse en LuKER, Abortion and the Politics of Motherhood, especialmente los caps. 3-7.

62381 U.S. 479 (1965).

63 Para un relato de esta historia, véase D. J. GARrow, 1993: The Right to Privacy and the Making of Roe v. Wade, New York: Lisa Drew Books.

64381 U.S. $479-84$ (1965).

65 Eisenstadt vs. Baird, 405 U.S. 453 (1972), cursivas en el original. 
sultado de Roe. Una es insistir que lo hecho por la Corte Suprema en Griswold no es inusual. Cada cláusula del Bill of Rights tiene que ser interpretada a la luz de supuestos filosóficos fundamentales ${ }^{66}$. Más aún, esta línea de respuesta funciona, ya que pocos críticos de Griswold querrían vivir con todas las implicaciones que se siguen de abandonar la noción de que hay un derecho a la intimidad constitucionalmente protegido. Efectivamente, quienes critican Roe, como el Subsecretario de Justicia del Presidente Ronald Reagan, Charles Fried, por lo general niegan que Griswold deba ser revocado ${ }^{67}$. Como R. DWORKIN — quizás quien formula la mejor defensa de Griswold y de su extensión a Roe - ha destacado, es difícil discernir un fundamento basado en principios para esta posición. Una vez que Griswold es aceptado, parece conducir inevitablemente a Roe, en parte porque la tecnología de la contracepción y el aborto se superponen (y quizás lo hagan cada vez más con el paso del tiempo) ${ }^{68}$, y en parte porque es difícil brindar razones convincentes para distinguir los casos entre sí.

El razonamiento de la Corte Suprema en Griswold fue que las decisiones que afecten al matrimonio y al parto son de un carácter tan íntimo y personal que las personas deben ser libres para tomar esas decisiones por sí mismas. Como advirtió DwORKIN, las decisiones en materia de aborto son por lo menos tan privadas como aquellas referidas a la contracepción; efectivamente, en un aspecto son más privadas porque la decisión de abortar «involucra el control de la mujer no sólo de sus relaciones sexuales sino también de las transformaciones que se producen en el interior de su propio cuerpo, y la Corte Suprema ha reconocido de diversos modos la importancia de la integridad física» ${ }^{69}$. Por lo tanto, DwORKIN defiende tanto Griswold como Roe, así como el rediseño hecho por la Corte Suprema de la doctrina de Roe en Casey a través del estándar de la «carga indebida» que coloca cargas gradualmente más severas a medida que el embarazo avanza sobre aquellas mujeres que desean interrumpir el mismo, que están diseñadas para lograr que ellas reflexionen sobre la seriedad de su intención de abortar y para favorecer el interés del Estado en proteger la vida humana potencial ${ }^{70}$.

Defender Roe sobre las bases de que no puede distinguirse de Griswold basándose en principios es recurrir a lo que en ultima instancia es un argumento ad hoc, algo que conservadores como Robert Bork se aprestan a señalar. Desde la izquierda, la doctrina Griswold ha sido también rechazada por feministas radicales en cuanto que ideología masculina que contribuye a la subyugación de las mujeres ${ }^{71}$. Efectivamente, en

${ }^{66}$ Véase R. DwORKIN, 1977: Taking Rights Seriously, Cambridge, Mass.: Harvard University Press, pp. 14-80.

${ }_{67}$ Como ha mantenido en un debate oral frente a la Corte en Webster en 1990. La excepción aquí es Robert Bork, quien argumentó en su audiencia de confirmación para la Corte Suprema que ambos Roe y Griswold deben ser revocados. Esta visión tiene el mérito de ser internamente consistente, pero está aún tan lejos de la corriente principal de la opinión jurisprudencial conservadora que llevó a muchos demócratas y republicanos conservadores en el Senado a oponerse a su nominación.

${ }_{68}$ Algunos dispositivos intrauterinos y muchas populares píldoras de control natal destruyen el óvulo fertilizado si fallan en evitar la fertilización.

${ }^{69}$ Dworkin, Life's Dominion, p. 107.

70 Aunque DwORKIN quisiera aplicar el estándar de un modo más permisivo del que lo hace la Corte. Por ejemplo, su posición es que la Corte debió haber derribado el período de espera compulsivo que afirmó en $C a$ sey (DwORKIN, Life's Dominion, pp. 172-174).

71 Véase C. MacKinnon, 1987: Feminism Unmodified: Discourses on Life and Law, Cambridge Mass.: Harvard University Press, pp. 93-102, y R. WeST, 1988: «Jurisprudence and Gender», University of Chicago Law Review, vol. 55, n. ${ }^{\circ}$ 1, pp. 67-70. 
otros contextos - tales como en la discusión por la promulgación de leyes sobre violación dentro del matrimonio- las feministas se han preocupado de debilitar la presunción del common law según la cual las relaciones maritales ocultan al Derecho penal los comportamientos $\left\langle i\right.$ intimos» ${ }^{72}$. En parte por estas razones, una línea alternativa de respuestas para lo que es percibido como la debilidad de Griswold y Roe ha sido propuesta por los defensores del derecho al aborto, una que echa por la borda totalmente el argumento de la intimidad y se apoya en cambio en el compromiso constitucional a la igual protección jurídica, explícita en la Enmienda Decimocuarta, e implícita en la Cláusula del Proceso con todas las garantías de la Enmienda Quinta.

$\mathrm{El}$ argumento de la igualdad gira en torno a la afirmación de que las restricciones sobre el aborto discriminan a las mujeres colocando límites a su libertad que, sin embargo, los hombres no tienen que soportar. Ésta fue la posición sostenida por la entonces jueza de la Corte Federal de Apelaciones, R. B. GINSBURG, en su Madison Lecture dictada en 1993 en la Universidad de New York. Dicha posición provocó un agudo interrogatorio en su audiencia de confirmación para la Corte Suprema porque revelaba su desacuerdo en relación con la doctrina de la intimidad de Roe ${ }^{73}$. A juicio de GINSBURG, las regulaciones sobre el aborto afectan «al control autónomo de una mujer sobre el completo curso de su vida — su capacidad para posicionarse en relación con el hombre, la sociedad y el Estado- como una ciudadana independiente y autosuficiente» ${ }^{74}$. En opinión de GINSBURG la Corte Suprema de Roe debería haberse «concentrado de un modo más preciso en la dimensión de la igualdad de la mujer de dicho problema», permitiéndole sostener que «el trato desventajoso a una mujer por razón de su embarazo y por razón de su capacidad de elegir en materia de reproducción es un caso paradigmático de discriminación por razón de sexo» ${ }^{75}$. Es cierto que los argumentos de igual protección han sido de una efectividad decreciente en las Cortes Supremas de Burger y Rehnquist, pero GINSBURG señala que en el mismo periodo en que Roe fue dictada la Corte Suprema tuvo un caso en su agenda que podría haber servido como puente, «vinculando la elección reproductiva con el trato desventajoso de las mujeres basado en su sexo» ${ }^{76}$. Siguiendo este orden de ideas, vio la decisión de optar por la línea de razonamiento de Griswold en Roe, como una oportunidad

72 Sobre la cambiante legislación de la violación marital en los Estados Unidos, véase M. FrEEMAN, primavera 1981: «If you Can`t Rape Your Wife, Who[m] can You Rape? The Marital Rape Exception Re-examined», Family Law Quaterly, vol. 15, n. ${ }^{\circ}$ 1, pp. 1-29; D. RoDHE, 1989: Justice and Gender, Cambridge, Mass.: Harvard University Press, pp. 249-251; R. I. Agustine, 1990-1991: «Marriage: The Safe Heaven for Rapists», Journal of Family Law, vol. 29, n. ${ }^{\circ}$ 3, pp. 559-590; y S. RYDER y S. KuZMENKA, invierno 1991: «Legal Rape: The Marital Exception», John Marshall Law Review, vol. 24, pp. 393-421. Sobre la evolución en Inglaterra

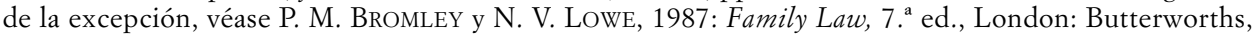
pp. 109-112.

${ }_{73}$ GINSBURG, 9 de marzo de 1993: «Speaking in Judicial Voice», Madison Lecture, New York University Law School, mimeo. Por las audiencias, véase «Nomination of Ruth Bader Ginsburg to be an Associate Justice of the United States Supreme Court: Report Together with Additional Views», Exec. Report 103-6-93-1 United States Senate, pp. 17-19.

${ }_{74}$ «Nomination of Ruth Bader Ginsburg», p. 17.

75 GinsBurg, Madison Lecture, pp. 24, 28. Para una defensa más elaborada de la opinión basada en la igualdad, véase S. A. LAW, 1983-1984: «Rethinking Sex and the Constitution», University of Pennsylvania Law Review, vol. 132, n. ${ }^{\circ}$ 2, pp. 1002-1013.

${ }^{76}$ GINSBURG, Madison Lecture, p. 24. El caso, Struck vs. Secretary of Defense, 409 U.S. 947 (1973), fue remitido por considerar que la cuestión se tornó abstracta. 
desperdiciada para situar el derecho al aborto sobre una base conceptual y constitucional más firme ${ }^{77}$.

Cualesquiera que sean los fundamentos jurisprudenciales para el derecho al aborto, se podría afirmar que la manera en que Roe fue decidido - tanto como el contenido de la decisión - era lo que iba a volver sospechosa su legitimidad. Después de todo, en Roe la Corte Suprema hizo mucho más que revocar una ley de Texas sobre el aborto. El voto por la mayoría presentó un test detallado que establecía las condiciones bajo las cuales podría esperarse que una ley sobre aborto fuera aceptable; de hecho, el juez Blackmun fue autor de su propia ley federal sobre aborto. GINSBURG defiende fuertemente la idea de que decisiones de este tipo tienden a socavar la legitimidad de la Corte Suprema. Cree que algunas veces es necesario para la Corte Suprema estar un paso «adelante» del proceso político a fin de lograr reformas que la constitución requiere, pero que en caso de adelantarse demasiado puede producir una reacción negativa y provocar acusaciones de que está excediéndose de su lugar apropiado en un orden constitucional democrático ${ }^{78}$.

Esta línea de razonamiento acerca del rol de la Corte Suprema ha sido desarrollada en forma más completa por R. BURT ${ }^{79}$. Este autor contrasta el tratamiento de la Corte Suprema del problema del aborto con el enfoque que la Corte Suprema adoptó en los casos de segregación racial escolar de la década de los cincuenta. En Brown vs. Board of Education of Topeka (1954), los jueces declararon que la doctrina de «separados pero iguales» era una violación inconstitucional de la Cláusula de Igual Protección [Equal Protection Clause] ${ }^{80}$, pero no describieron las condiciones de escolaridad que serían aceptables. Más bien, devolvieron el problema a los legisladores de los Estados sureños, exigiéndoles que diseñaran por ellos mismos remedios aceptables ${ }^{81}$. Estos remedios llegaron ante la Corte Suprema como resultado de los posteriores litigios, fueron examinados en tales ocasiones y frecuentemente fueron considerados deficientes ${ }^{82}$. Pero la Corte Suprema evitó diseñar ella misma el remedio, y con ello la acusación de que estaba usurpando la función legislativa. En Roe, en cambio, como lo expone GinsBURG, la Corte Suprema «no invitó a los legisladores al diálogo. En vez de esto, parece más bien que apartó la pelota completamente del campo de los legisladores» aniquilando virtualmente cualquier forma de regulación del aborto existente por entonces ${ }^{83}$.

Según GiNSBURG y BURT, el holding radical de Roe disminuía la legitimidad democrática de la Corte Suprema, al mismo tiempo que se anticipaba a una variedad de esquemas que habían estado diseñándose en diferentes Estados para hacer más liberales las leyes sobre el aborto. Entre 1967 y 1973, en diecinueve Estados fueron aprobadas

${ }_{77}$ Por supuesto que es posible que Blackmun hiciera campaña por esta posibilidad y que pudiera no encontrar apoyo para ella entre sus compañeros miembros de la Corte aunque, dado su fracaso, sólo por mencionarlo, parece más probable que, como R. DwORKIN, Blackmun simplemente pensó que Griswold era obligatorio.

${ }^{78}$ GinsBuRg, Madison Lecture, pp. 30-38.

79 R. A. BurT, 1992: The Constitution in Conflict, Cambridge, Mass.: Harvard University Press, pp. 344-352.

80 Brown vs. Board of Education I, 347 U.S. 483 (1954).

${ }^{81}$ Brown vs. Board of Education II, 349 U.S. 294 (1955).

82 BuRT, Constitution in Conflict, p. 348.

${ }^{83}$ Ginsburg, Madison Lecture, p. 32. 
leyes que hicieron más liberales los motivos que permitían el aborto. Muchas feministas habían estado insatisfechas con el ritmo y el alcance de esta reforma y lanzaron la campaña que ayudó a provocar el resultado de Roe. BuRT admite que en 1973 estaba «poco claro si las leyes estatales recientemente promulgadas significaban el comienzo de una tendencia nacional hacia la derogación de todas las restricciones sobre el aborto o incluso si en los denominados Estados más liberales, las nuevas promulgaciones aumentarían significativamente el acceso al aborto para cualquiera». No obstante, insiste en que «el problema del aborto era discutido abierta y ávidamente en un importante cantidad de foros públicos, y a diferencia del ordenamiento existente en una fecha tan reciente como 1967, ya no era claro quién estaba ganando la batalla» ${ }^{84}$. Siguiendo el modelo de Brown, la Corte Suprema podría haber anulado la ley de Texas sobre el aborto en Roe (ya sea apelando al argumento de la intimidad de Blackmun o al de la igualdad apoyado por GINSBURG y otros) sin proceder a desarrollar y aplicar el esquema trimestral de Blackmun. Esto habría establecido algunos límites sobre lo que las legislaturas podrían hacer en materia de regulación del aborto sin involucrar a la Corte Suprema directamente en el diseño de la misma. En opinión de GINSBURG y BURT, esto habría dejado espacio para que el conflicto se resolviera democráticamente, lo que habría asegurado la supervivencia del derecho al aborto, preservando al mismo tiempo la legitimidad del rol de la Corte Suprema en un orden constitucional democrático ${ }^{85}$.

\section{EL FUTURO DEL DERECHO CONSTITUCIONAL AL ABORTO}

Es irónico, quizás, que aunque Casey fue decidido antes del ascenso de GINSBURG a la Corte Suprema, aquella decisión alineó la posición de la Corte Suprema con la postura de GINSBURG y BURT sobre el modo en que debería enfocarse la problemática del aborto. Al afirmar la existencia del derecho constitucional fundamental de una mujer al aborto, al reconocer la legitimidad del interés estatal en la vida potencial, y al insistir en que los Estados no pueden perseguir la reivindicación de este interés de un modo que sea indebidamente gravoso para las mujeres, la Corte Suprema estableció algunos parámetros básicos dentro de los cuales el legislativo debe a partir de entonces diseñar reglas que reglamenten el aborto. Los disidentes en Casey tenían razón al señalar que existiría cierto grado de impredictibilidad y confusión en la medida en que se promulgarían diferentes sistemas normativos en diferentes Estados, y en la medida en que serían examinados por los tribunales ${ }^{86}$. Particularmente dada la dimensión progresiva del

${ }^{84}$ BurT, Constitution in Conflict, p. 348.

${ }^{85}$ Ibidem, pp. 349-352.

${ }^{86}$ En su opinión parcialmente disidente, Rehnquist — junto con White y Scalia- dijo respecto de la opinión dominante en Casey: «El resultado final del himno glorificante de la legitimidad al que apeló la opinión conjunta en este caso es el enunciado de un estándar completamente nuevo para evaluar las regulaciones estatales sobre el derecho de una mujer al aborto —el estándar de la "carga indebida"—Roe vs. Wade adoptó un estándar de "derecho fundamental" bajo el cual las regulaciones estatales podían sobrevivir sólo si satisfacían los requisitos del "escrutinio estricto". Aunque estemos en desacuerdo con ese estándar, éste al menos había admitido un fundamento en el Derecho constitucional en la época en que Roe fue decidido. Lo mismo no puede decirse del estándar de la "carga indebida", el cual es creado en su totalidad por los autores de la opinión conjunta. Es un estándar que aún hoy no dispone del apoyo mayoritario de esta Corte. Y creemos que no acabará por ser un tipo de "simple limitación" de aplicación fácil, como auspicia la opinión conjunta» [112 S. Ct. 2791, en p. 2866 (1992)]. 
examen — que permite reglas cada vez más gravosas a medida que avanza el embarazo- esto es inevitable. Quienes consideran que en el desarrollo de la función judicial se ha de dar prioridad a la eficiencia y a la claridad sobre todo lo demás, esto podría parecer una objetable provocación de litigios posteriores ${ }^{87}$. Para la posición GINSBURG y BURT, sin embargo, la tendencia de Casey a provocar litigios puede ser un costo que merezca ser pagado. Al igual que Brown, sitúa sobre los legisladores democráticamente elegidos la responsabilidad de proponer modos de regular el aborto que no graven indebidamente a las mujeres, y las constriñe a hacer esto con el conocimiento de que las leyes que promulguen serán examinadas por los tribunales y desechadas si son consideradas deficientes. Esto da motivos a los legisladores para diseñar sistemas de reglas que minimicen las cargas colocadas sobre las mujeres cuando ellos procuran defender los intereses legítimos de los Estados en proteger la vida potencial. También asigna a los tribunales federales un rol legítimo en una democracia constitucional. «Sin dar grandes zancadas y por ello arriesgarse a una reacción negativa demasiado fuerte de contener, la Corte Suprema, a través de la adjudicación constitucional, puede reforzar o dar luz verde al cambio social» ${ }^{88}$.

Adoptando el enfoque de GINSBURG y BURT sobre el modo en que son encaradas las regulaciones del aborto, la Corte Suprema ha comenzado probablemente a desmentir la afirmación de A. MACINTYRE — mencionada en el comienzo de este trabajo- de que las diferentes partes de la controversia respecto del aborto actúan desde visiones inconmensurables de la vida entre las que es imposible la evaluación racional. Por el contrario, como el debate se ha trasladado desde imponderables metafísicos - respecto de cuándo comienza la vida y si el feto es una persona- hacia consideraciones acerca de qué constituye una carga indebida sobre los derechos constitucionalmente protegidos de una mujer, ha quedado claro que existe un amplio espacio para los argumentos racionales sobre el derecho legal al aborto. Que el aborto pueda ser un asunto políticamente polarizador no significa que tenga que ser polarizado. Es ciertamente una ventaja del enfoque de Casey el que empuje el debate lejos de problemas que no pueden ser resueltos en una cultura pluralista y hacia áreas donde una solución negociada y un acuerdo podrían estar disponibles.

Dejando a un lado los problemas de enfoque, el contenido del estándar de la «carga indebida» ofrece posibilidades para limitar las regulaciones del aborto que pueden ser más robustas de lo que los críticos de Casey hayan podido apreciar. Ciertamente parece ser una estrategia interpretativa plausible afirmar como consecuencia de Casey, como lo hace R. DwORKIN, que cualquier regulación de las decisiones sobre el aborto debería ser considerada innecesariamente coercitiva y por tanto «indebida» si el mismo «incemento de la responsabilidad en la toma de decisiones sobre si interrumpir o no un embarazo pudo haber sido alcanzado por una vía diferente con consecuencias menos coercitivas» ${ }^{89}$. Esta línea de razonamiento sugiere que si los demandantes pue-

${ }^{87}$ Véanse los comentarios de Rehnquist inmediatamente a continuación de aquellos citados en la nota al pie precedente. Para una defensa más general de la eficiencia en la sentencias de apelación federales, véase $\mathrm{R}$. Posner, 1985: The Federal Courts: Crisis and Reform, Cambridge, Mass.: Harvard University Press, pp. 169315. Para una crítica a la opinión de POSNER véase mi «Richard Posner`s Praxis», Obio State Law Review, vol. 48, n. ${ }^{\circ}$ 4, 1987, pp. 1009-26.

${ }^{88}$ Ginsburg, Madison Lecture, p. 36.

${ }^{89}$ Dworkin, Life's Dominion, p. 173. 
den mostrar que regulaciones menos restrictivas pueden alcanzar los objetivos estatales perseguidos al regular el aborto, las regulaciones existentes tendrán que ser anuladas. Conociendo esto, las legislaturas que se encuentran contemplando la posibilidad de sancionar leyes sobre el aborto tendrán motivos para no adoptar regulaciones más restrictivas que aquellas que puedan ser justificadas como necesarias.

Pero, quizás el rasgo más importante y menos tenido en cuenta del estándar de la «carga indebida» alrededor del cual ha comenzado a girar la normativa constitucional sobre aborto desde Casey sea su potencial para estimular las consideraciones igualitaristas que Blackmun soslayó cuando recurrió a la doctrina de la intimidad de Griswold como el fundamento para su opinión en Roe. La razón es que probablemente resultará extremadamente difícil forjar una jurisprudencia de las cargas debidas e indebidas sin aludir a consideraciones igualitaristas. Un indicio de esto puede encontrarse en los votos de Casey. Los disidentes en ese caso señalaron que es difícil encontrar un fundamento basado en principios para sostener, por un lado, que las exigencias de la notificación conyugal imponen cargas indebidas sobre las mujeres porque algunas mujeres posiblemente enfrenten maridos abusivos y al mismo tiempo sostener, por otro lado, que las exigencias del consentimiento de los padres no lo hacen, aun cuando, presumiblemente, algunas adolescentes embarazadas enfrentarán padres abusivos ${ }^{90}$. DWORKIN extiende esta crítica, señalando que es no menos difícil encontrar un fundamento basado en principios para el rechazo de la Corte Suprema a la pretensión de que un periodo de espera de veinticuatro horas no supera el test de la carga indebida, aun cuando es admitido por la Corte Suprema que sitúa una carga comparativamente pesada sobre las mujeres pobres. En su opinión, si una restricción que no hace al aborto imposible en la práctica para ninguna mujer, no obstante «lo hace lo suficientemente más caro o dificultoso de modo que disuadirá a algunas mujeres de practicarse un aborto que, luego de reflexionar, quieren hacer», no tendría que superar el test de la carga indebida ${ }^{91}$. La lógica de DwORKIN es difícil de resistir una vez que la Corte Suprema ha adoptado la idea según la cual una regulación que pueda imponer altos costos sobre algunas mujeres no es constitucionalmente aceptable por esa razón. Aunque este argumento no es explícitamente igualitarista, implícitamente lo es porque sugiere que, para subsistir, las regulaciones del aborto no deben imponer cargas sobre las mujeres de bajos ingresos por el mero hecho de ser pobres.

El razonamiento de DwORKIN está enraizado en el hecho de que es difícil —quizás imposible - dar sentido a la idea de «lo debido» sin referencias a la idea de igualdad. Esto, seguramente, no está mejor ilustrado en ningún lugar más que en la evolución del concepto de debido proceso en el procedimiento penal estadounidense, y podría ser esclarecedor aquí mencionar algunas semejanzas posibles entre esa historia y un futuro posible para el estándar de la carga indebida en la normativa constitucional sobre aborto.

El famoso caso de 1963 Gideon vs. Wainwright estuvo centrado en el problema de si los Estados debían proveer de asesoramiento legal pagado por el gobierno a los criminales indigentes acusados en casos de delitos castigados con la pena de muerte ${ }^{92}$. La

\footnotetext{
90 120. L. Ed. 2d 674, en pp. 774-97 (1992).

91 Dworkin, Life's Dominion, p. 173.

92 Para una descripción excelente, véase A. LEWIS, 1966: Gideon's Trumpet, New York: Vintage.
} 
Corte Suprema sostuvo que debían hacerlo, parcialmente sobre la base de que los acusados adinerados están claramente en posición de contratar asesoramiento ${ }^{93}$. En las décadas siguientes a Gideon, la noción de que las personas pobres no deberían soportar aquellas cargas en la persecución de sus derechos constitucionalmente protegidos que las personas ricas no tienen que soportar, quedó enclavada en la noción de debido proceso penal. Como resultado, robustas protecciones fueron incorporadas a la legislación del procedimiento penal en las décadas de los sesenta y setenta en relación con el derecho al asesoramiento tanto en apelaciones como en juicios, para delitos no castigados con la pena de muerte si el acusado va a ser encarcelado en caso de ser considerado culpable, y ámbitos relacionados ${ }^{94}$. Es verdad que las lecturas igualitaristas de la Cláusula del debido proceso [Due Process Clause] en el procedimiento penal fueron posteriormente reducidas por las Cortes de Burger y Rehnquist ${ }^{95}$. Esto enfatiza el hecho de que el Derecho no siempre evoluciona en una dirección. De ningún modo es necesario que las interpretaciones fuertemente igualitaristas de la idea de «lo debido» prevalezcan siempre en este ámbito o en cualquier otro. No obstante, las consideraciones igualitaristas no han sido completamente abandonadas por la Corte Suprema en este ámbito y, a veces, aun cortes conservadoras las han desarrollado - como en 1985 cuando sostuvieron que a un acusado indigente que ofrece una excusa por enfermedad mental debería concedérsele tener su propio psiquiatra designado por la corte a cargo del gobierno ${ }^{\%}$. Una vez más la idea de «lo debido» de la Cláusula del Proceso con todas las garantías fue desentrañada por referencia a la igualdad.

No requiere gran cantidad de imaginación discernir las posibilidades creativas que tendría para un razonamiento análogo que los tribunales federales vayan desentrañando el significado de «carga indebida» en la normativa constitucional sobre el aborto. Que una carga no puede considerarse debida si impone costos sustanciales sobre algunas mujeres es algo que tiene asidero en el lenguaje de la opinión dominante en Casey, como hemos visto, aunque, como sucedió en el caso del debido proceso en el procedimiento penal, las implicaciones de esto son contradictorias en las opiniones de la Corte Suprema y todavía tienen que ser completamente desarrolladas. Un área obvia que podría ser explorada se refiere al financiamiento del aborto. Así como se sostuvo que el derecho constitucional a ser asesorado de Clarence Earl Gideon exigía al gobierno designar un asesor jurídico a cargo del Estado para los acusados indigentes en ciertas circunstancias, uno puede imaginar argumentos análogos siendo explorados en el contexto del aborto. Cuáles resultarían ser las clases de circunstancias semejantes es difícil de saber por adelantado, pero casos de violación —en donde la embarazada no tiene ninguna responsabilidad presunta por su embarazo- son un lugar obvio para comenzar. Desde el punto de vista de las feministas radicales, esto podría parecer una ganancia potencial pequeña dado lo que se ha perdido desde Webster y Casey, pero dado que la Corte Suprema en el pasado nunca ha visto favorablemente a los demandantes que

93372 U.S. 335 (1963).

${ }_{94}$ Para ejemplos, véase Douglas vs. California, 372 U.S. 353 (1963) y Argesinger vs. Hamlin, 407 U.S. 25 (1972).

${ }_{95}$ Véase Ross vs. Muffitt, 417 U.S. 600 (1974); Scout vs. Illinois, 440 U.S. 367 (1979); United States vs. Cronic, 466 U.S. 648 (1984); y Strickland vs. Washington, 466 U.S. 668 (1984).

96 Akevs. Oklahoma, 470 U.S. 68 (1985). 
buscan financiación para abortar, una ganancia potencial en esta área no debería ser considerada insignificante desde su punto de vista.

Las posibilidades igualitaristas no se agotan por extraer las implicaciones de la tesis según la cual ha de considerarse que las regulaciones que imponen cargas sustanciales sobre algunas mujeres no superan el test de la «carga indebida». Casey identifica dos fuentes del interés del Estado en regular el aborto: para asegurar que la mujer ha dado su consentimiento informado al procedimiento abortivo, y para defender el interés del Estado en la protección de la vida potencial. El primero de estos intereses toma en consideración al individuo en el sentido de que el Estado puede alentar a la mujer que está considerando practicarse un aborto a reflexionar sobre la gravedad del curso de acción que se ha propuesto y a considerar alternativas, en tanto esto no grave innecesariamente su decisión. El interés estatal aquí reside en la calidad de la decisión de la mujer: ésta debería ser genuina e informada. Como he señalado, las consideraciones igualitaristas implícitamente afectan la evaluación de las regulaciones diseñadas para alcanzar este objetivo porque las mismas regulaciones que pueden no ser gravosas para mujeres adineradas pueden, sin embargo, imponer costos importantes sobre las mujeres de bajos ingresos.

Un tipo diferente - y potencialmente más fuerte- de consideración igualitarista surge, sin embargo, una vez que reflexionamos sobre la regulación del aborto por parte del Estado para reivindicar su interés en la vida humana potencial. Esto abre la posibilidad de recuperar las consideraciones sobre igual protección que GINSBURG, C. MACKInNON, R. WeST y otros piensan que fueron perdidas cuando Blackmun decidió basar Roe en la doctrina de la intimidad de Griswold. ¿Por qué, puede y será preguntado, deberían los Estados tener permitido defender este interés de un modo que pueda suponer imponer desproporcionadamente los costos de este accionar sobre algunas mujeres o, efectivamente, sobre las mujeres en vez de sobre los hombres? Las posibilidades ofrecidas por esta línea de pensamiento son difíciles de percibir en abstracto. La Corte Suprema en la década de los noventa y en la primera década de 2000 se mantuvo claramente impermeable a la visión feminista de que virtualmente cualquier regulación del aborto discrimina a las mujeres y debería ser rechazada por esa razón ${ }^{97}$. Pero la oportunidad para un argumento basado en la igual protección está al acecho en la lógica de Casey, si acaso no lo hace en su lenguaje, y parece al menos posible que esta lógica pudiese generar importantes restricciones a las regulaciones del aborto en el futuro.

Ocho años después de Casey había indicios de que las consideraciones igualitaristas estaban moldeando la jurisprudencia sobre el aborto de la Corte Suprema. El párrafo introductorio del voto por la mayoría del juez Breyer en su polémica decisión sobre el aborto por nacimiento parcial, Stenberg vs. Carhart (2000), señala que millones «temen que una ley que prohíba el aborto condenaría a muchas mujeres estadounidenses a vidas que carecen de dignidad, privándoles de igual libertad y llevando a aquéllas con menos recursos a someterse a abortos ilegales con los riesgos concomitantes de muerte y sufrimiento» ${ }^{98}$. La decisión en Gonzales vs. Carbart (2007), que revirtió el re-

\footnotetext{
97 Véase nota al pie 71.

98192 F. 3d 1142, la cursiva es mía.
} 
sultado de Stenberg, no repudió esta lógica igualitarista. Ciertamente, aspectos del voto por la mayoría del juez Kennedy podrían ser interpretados como paternalistas, si no condescendientes, hacia las mujeres — tal como la afirmación de que las mujeres que no aprecian completamente lo que el procedimiento $\mathrm{D} \& \mathrm{X}$ involucra podrían posteriormente quedar traumatizadas si se enterasen de lo que involucra luego del hecho-Como la jueza GiNSBURG señaló en su voto en disidencia, esto difícilmente sea una base para distinguir el procedimiento $\mathrm{D} \& \mathrm{X}$ del $\mathrm{D} \& \mathrm{E}$, y supone que las mujeres están de algún modo incapacitadas para tomar decisiones según sus propios y mejores intereses ${ }^{99}$. Pero la mayoría no puso en cuestión la idea de que la carga indebida exige que todas las mujeres tengan acceso al procedimiento abortivo más seguro disponible, afirmando de ese modo, al menos implícitamente, un compromiso con la igualdad de las mujeres.

El debate era sobre si el procedimiento $\mathrm{D} \& \mathrm{X}$ es más seguro en algunas circunstancias. En Stenberg, los tribunales inferiores habían encontrado que existía, en efecto, un conjunto importante de opiniones procedentes de autoridades médidas favorable a la opinión del médico generalista acerca de que el procedimiento D\&X era el más seguro disponible en ciertas circunstancias. Esta supuesta mayor seguridad fue discutida por los jueces disidentes Rehnquist, Kennedy, Thomas y Scalia. Antes que debatir las opiniones controvertidas acerca de la ciencia con los disidentes, la mayoría habría hecho mejor en adoptar la posición de que, como se trata de una controvertida cuestión de hecho, es mejor que sea dirimida por el tribunal que haya de conocer del caso particular en cuestión. Si la legislatura de Nebraska hubiese tenido en cuenta la evidencia de la seguridad relativa de los distintos procedimientos, el momento oportuno para establecer esto era el juicio, y si el doctor Carhart cuestionaba el fundamento científico sobre el que se basaba el dictamen, él, también, habría tenido que persuadir al tribunal que estuviera conociendo del caso en cuestión. Quizás la legislatura de Nebraska no tuvo en cuenta la cuestión en absoluto, en cuyo caso la idea de que ella está mejor posicionada que una corte de apelación para hacer esta determinación, como alegaron los disidentes, sería irrelevante.

Las cortes de apelación no escuchan a los testigos ni a los testimonios de expertos. Como resultado, en general no se supone que revisen las determinaciones fácticas del tribunal inferior. A menos que los registros contengan evidencia abrumadora de que las determinaciones del inferior no pueden ser creídas, las determinaciones fácticas tienen que ser generalmente aceptadas tal cual. Y aun cuando haya una razón para dudar de ellas, el remedio apropiado es remitir el caso al tribunal que conoció el caso en cuestión para un nuevo examen de la causa, no hacer una determinación diferente de los hechos durante el proceso de revisión por un tribunal de apelación. Desde esta perspectiva los disidentes en Stenberg, no la mayoría, inapropiadamente confiaban en su propia (falta de) habilidad en la resolución de las cuestiones de hecho controvertidas.

El Congreso elevó la apuesta en respuesta a Stenberg entrando en el juego con la determinación de que el procedimiento $\mathrm{D} \& \mathrm{X}$ nunca es médicamente necesario, e introduciendo esta determinación en su Ley de probibición del aborto por nacimiento parcial. Pero los tribunales federales nunca han deseado en exceso mostrar total deferen-

99127 S. Ct. 1610, en 1648-9 (2007). 
cia a las determinaciones legislativas relativas a cuestiones de hecho. Como lo expresaba el juez Thomas mientras se desempeñaba en el Tribunal de Apelaciones del Distrito de Columbia antes de su ascenso a la Corte Suprema, «[Si] una legislatura pudiera hacer constitucional una ley simplemente por "determinar" que el negro es blanco o que la libertad es esclavitud, la revisión judicial sería una sofisticada farsa. Al menos desde Marbury vs. Madison (1803) [...] ese no ha sido el Derecho» ${ }^{100}$. En vista de las afirmaciones infundadas, los errores fácticos y los testigos parcialmente competentes que acompañaron esta determinación del Congreso, es poco sorprendente que los tribunales inferiores no hayan sido convencidos. En efecto, el voto por la mayoría del juez Kennedy en Gonzales no defiende la práctica según la cual corresponde al Congreso establecer los hechos. Más bien, toma la postura de que hay «incertidumbre médica» respecto de la cuestión de si el procedimiento $\mathrm{D} \& \mathrm{X}$ es más seguro para la mujer en algunas circunstancias, y que esta incertidumbre «no excluye el ejercicio del poder legislativo» ${ }^{101}$. En efecto, quizás no lo excluye, pero tampoco implica que los tribunales deberían mostrar deferencia hacia ese poder cuando está basado en determinaciones fácticas manifiestamente implausibles.

No quedó claro si el resultado en Gonzales de hecho había acercado a la Corte Suprema a abandonar la reafirmación de Casey del derecho constitucionalmente protegido de una mujer a un aborto. La disidencia de GINSBURG sugería que sí lo había hecho y comentarios de académicos pro elección tales como DWORKIN no auguran nada bueno al respecto ${ }^{102}$. Fiel a las formas, dadas sus opiniones previas, la jueza Thomas escribió un conciso voto concurrente reiterando su postura de «que la jurisprudencia sobre aborto de la Corte Suprema, incluyendo Casey y Roe vs. Wade [...] no tiene fundamentos en la Constitución» ${ }^{103}$. El juez Scalia se unió al voto concurrente de Thomas. Esto, tampoco fue una sorpresa. Pero en tanto que en el pasado el nombre de Rehnquist habría estado allí también, ninguno de los dos nuevos jueces - Roberts y Alito- optaron por unirse a la opinión de Thomas y Scalia. Esto puede haber indicado un acuerdo con Kennedy acerca de que la garantía del derecho al aborto de Casey permanece intacta si bien el test de la carga indebida no resultaba satisfecho en este caso en cuestión. Pero puede haber significado que ambos o uno de los nuevos jueces se encontraban indecisos sobre el asunto más amplio o, si decididos, estaban poco dispuestos a poner sus cartas sobre la mesa por el momento. Sólo el tiempo lo dirá.

\section{(Traducción de Hugo O. Seleme, Cristián A. Fatauros y Natalia Arreguine)}

${ }^{100}$ Lamprecht vs. FCC, 958 F. 2d, 382, 392 (DC Circuit 1992).

${ }^{101} 127$ S. Ct. 1610, en p. 1618 (2007).

102 Dworkin, 31 de mayo de 2007: «The Court and Abortion: Worse Than you Think», New York Review of Books, vol. 54, n. ${ }^{\circ}$ 9, pp. 20-21.

${ }^{103} 127$ S. Ct. 1610, en pp. 1639-1640 (2007). 
